\title{
Sexual dimorphism in cognition and behaviour: the role of X-linked genes
}

\author{
David H Skuse \\ Behavioural and Brain Sciences Unit, Institute of Child Health, 30 Guilford Street, London WC1N 1EH, UK \\ (Correspondence should be addressed to D H Skuse; Email: dskuse@ich.ucl.ac.uk)
}

\begin{abstract}
Chimpanzees and humans last shared a common ancestor between 5 and 7 million years ago; 99\% of the two species' DNA is identical. Yet, since the paths of primate evolution diverged, there have been remarkable developments in the behavioural and cognitive attainments of our species, which ultimately reflect subtle differences in gene structure and function. These modifications have occurred despite evolutionary constraints upon the diversity of genetic influences, on the development and function of neural tissue. Significant species differences can be observed both at the levels of function (gene expression) and structure (amino acid sequence). Protein evolution is driving an accelerating increase in brain complexity and size. Playing centre stage, in terms of the proportion of genes involved in brain development and cognitive function, is the X chromosome. Recently, it has become clear that a long-standing theory, implicating X-linked genes in a sexually antagonistic evolutionary role, is probably correct. Genes on the sex chromosomes can directly influence sexual dimorphism in cognition and behaviour, independent of the action of sex steroids. Mechanisms by which sexchromosomal effects, due to X-linked genes, influence neural development or function are reviewed. These include the biased expression of genes subject to X-inactivation, haploinsufficiency (in males) for non-inactivated genes with no Y homology, sex-specific brain functions and genomic imprinting of Xlinked loci. Evidence supporting each of these mechanisms is available from both human and animal models. Recently, the first candidate genes have been discovered.
\end{abstract}

European Journal of Endocrinology 155 S99-S106

\section{Evolution and the sex chromosomes}

Chimpanzees and humans last shared a common ancestor between 5 and 7 million years ago. In crude terms, $99 \%$ of the two species' DNA is identical. Yet, since our paths of evolution diverged, that $1 \%$ of genetic difference has changed humans substantially, in terms of our behavioural and cognitive traits - presumably driven to a large extent by positive Darwinian selection. In this article, the evidence for evolutionary changes in terms of gene structure and gene expression in brain will be discussed, followed by a review of the specific characteristics of the $\mathrm{X}$ chromosome and its potential role in the development of sexually dimorphic characteristics.

We can now compare chimpanzee and human genomes, both in expression patterns of associated genes (transcriptomes) and in DNA structure (genomes). Evolutionary pressures that distinguish us from

\footnotetext{
This paper was presented at the 4th Ferring Pharmaceuticals International Paediatric Endocrinology Symposium, Paris (2006). Ferring Pharmaceuticals has supported the publication of these proceedings.
}

our nearest primate cousins can be summarized both in terms of transcriptome and genome, by comparing variation between individuals within a species (human or chimpanzee in this instance) and variation between species. In order to identify evidence for positive selection, a measure of divergence to diversity is calculated. Comparisons are made to a common ancestor of both chimps and humans, the so-called out-group method. In practice, the out-group chosen usually comprises macaque monkeys, which last shared a common ancestor with us at least 20 million years ago (2). A high ratio of gene expression divergence between species, to gene expression diversity within species, could imply positive selection. Evolutionary constraints upon gene expression are generally greater for genes that are ubiquitously expressed, than for those with restricted expression in one tissue (e.g. brain). Ubiquitously expressed genes differ less among individuals both within and between species, than do genes expressed in single tissues (1). Khaitovich et al. (1) found substantial expression divergence for X-linked genes in testes comparing humans to chimpanzees (but low diversity within species). The above finding supports the theory that X-linked loci can evolve rapidly and 
influence sexual development, if there is an evolutionary advantage to males (3). Gene expression patterns tend to differ less between humans and chimpanzees in the brain than in most other tissues measured (1) presumably because of the greater impact of constraints. However, it is possible to estimate the relative magnitude of rate of change in gene expression, comparing chimpanzees and humans over the past 5 million years. This rate of change has been greater in the human lineage, particularly in brain. Expression divergence between species has mainly involved upregulation. Compared with the out-group macaque, up to $92 \%$ of human genes are upregulated in the brain (a much higher proportion than in other tissues), many of which are involved in neuronal functions, synaptic activity and metabolism (4).

Evolutionary pressure on gene structure, in terms of alterations in the DNA sequence, can be estimated by comparing synonymous nucleotide substitutions with non-synonymous substitutions. High ratios could indicate positive selection for a functionally different gene. Genes that are expressed in brain (whether ubiquitous or not) have relatively few structural variants within and between species, a similar picture to that observed for gene expression (1). There have nevertheless been potentially functionally significant changes in DNA sequence for genes expressed in brain: the average rate of protein evolution for nervous system genes is much higher in primates than in rodents (measuring both from an independent common ancestor; for rodents, the common ancestor of rat and mouse) (5). When we compare the changes in gene structure since our last common ancestor, we find accelerated evolution for genes involved in brain development and cognitive function in humans, compared with chimpanzees (6), reflected in relatively more dramatic changes in brain complexity and size.

\section{Sexual selection}

Characteristics that are selectively favoured in one sex, but selected against in the other sex, are known as 'sexually antagonistic'. If selection acts on existing genetic variation within a population, a sexually dimorphic trait will evolve from the initial monomorphic state. Genes advantaging males will increase the chances of their passing on those genes to the next generation (8). The evolution of the $\mathrm{X}$ chromosome is intrinsically linked to the evolution of the Y chromosome (9), and Y-linked genes are obligatorily sexually dimorphic. Could X- or Y-linked genes directly influence the development and function of neural tissues in a sexually dimorphic way, independent of the action of sex steroids? Evidence was initially found in the Zebra finch. This songbird is sexually dimorphic in the production of vocalizations (males sing). The genetic sex of the brain directs masculinization independent of gonadal influences (10). One cannot induce the female to sing by giving male sex hormone. Either one can cause the males to desist from singing by castration early in life, or by blocking sex steroid receptors. Art Arnold (11) has been the main proponent of a view that sex chromosomes directly influence sexual differentiation in mammals as well as birds (which have a completely different sex-chromosome system).

Sexually dimorphic influences on human cognition and behaviour may affect the phenotypic expression of 'disorders' and 'traits' . 'Disorders' are sporadic/heritable abnormalities due to non-functional or otherwise mutated genes. 'Traits' represent normal variation in sexually dimorphic characteristics. X-linked disorders, such as fragile $\mathrm{X}$ syndrome or Rett syndrome, are sexually dimorphic in their expression but they represent extreme cases - dysfunction of a critical gene, even though expression of that gene might be neither dominant nor recessive in the conventional Mendelian sense (12). X-linked behavioural traits, quantitative variants, include male aggression and parental behaviour (13). Sexually dimorphic cognitive traits include spatial orientation; in rodents, male spatial learning advantages observed in the radial or water maze are caused by male-female differences in strategy selection. Females (rats and humans) navigate preferentially using landmarks, but males rely on a broader set of spatial representations (14). These traits are probably influenced by a Y-linked locus (15), although an X-linked locus may play a contributory role (16). During evolution, could X-linked genes for specific cognitive abilities, and a female preference for males who demonstrate those traits, have become closely linked, and hence jointly inherited (17)? Owing to the obligatory expression of all X-linked genes in males, any X-linked trait that is advantageous to males (or to females) would spread rapidly in the population. 'If higher cognitive abilities were a critical step in our own evolution, it makes sense that you might find those functions on the X-chromosome' (Willard, quoted by Erica Check (7)).

\section{Cognition, behaviour and the $\mathrm{X}$ chromosome}

It is estimated that there are 807 protein-coding genes on the $\mathrm{X}$ chromosome (Ensembl v37), together with many others coding for RNAs. In 2006, Online Mendelian Inheritance in Man recorded 1329 entries for 'mental retardation'. Of these, $342(25.7 \%)$ mapped to the X chromosome, suggesting X-linked genes play a disproportionate role in the development of human intelligence. Why should there be such a concentration on this particular chromosome (18)? One possible 
explanation is that the apparent concentration is a consequence of ascertainment bias; it is much easier to spot mutations that affect general intelligence on the sex chromosomes because, even if expression is recessive, the phenotype will express in males. However, that is unlikely to be the whole story. Although X-linked genes are highly expressed in the brain tissue of several mammalian species, normalized expression of X-linked genes in human brain tissue (compared with autosomal genes) is particularly high (19). Considering only genes that are mainly expressed in brain, humans have an exceptionally large proportion of X-linked genes with very biased expression. This suggests specialization of X-linked genes could be driving human cortical complexity and brain size. The $\mathrm{X}$ chromosome has been engaged in the development of sexually selected characteristics for at least 300 million years (20). If it has become a repository for genes specifically and highly expressed in brain, enhancing cognitive functions, this might have afforded a selective advantage to males in sexual reproduction (17). Some have argued males are more likely than females to be influenced by X-linked haplotypes associated with exceptionally high cognitive abilities in limited domains, but they are also more likely to show deficits in mental abilities than females because of the impact of deleterious mutations carried in haploid state (the X-linked 'male extremes' theory).

Why is there an excess of males in fields such as mathematics or engineering? The view that this is due to greater aptitude, or cognitive abilities in relevant areas, is by no means generally accepted (21). Perhaps males have more interest in the physical world, and in the relationships between objects, than females; if so, attainment could follow motivation (22). Whether advantageous genetic influences do account for the excess of male scientists, there is undoubtedly an excess of males with specific learning difficulties, such as developmental reading disability (23). Males are not generally more intelligent; a recent claim that male university students in general have significantly higher IQs than their female counterparts (24) was flawed by poor scientific methodology (25). Some X-linked genes have relatively specific effects on social cognition and emotional regulation. Mutations in two X-linked genes encoding neuroligins NLGN3 and NLGN4 have been found in siblings with autistic spectrum disorders (26). One of these (NLGN4) was located at Xp22.3, a region where previously de novo deletions had been observed in autistic females (27). Subsequently, another family has been identified with similar phenotypic associations (28). Whilst there is no evidence that allelic variation in the X-linked neuroligin genes influence susceptibility to autism in the general population $(29,30)$, Asperger syndrome and attention deficit hyperactivity disorder (32) are substantially more common in males than females (31), implying X-linked genes could be playing a role in male susceptibility to these disorders.

\section{Mechanisms of sexual dimorphism involving X-linked genes}

Mechanisms of sexually dimorphic gene expression in the brain include the following: first, genes subject to random $\mathrm{X}$-inactivation in females will be fully expressed from the male's single $\mathrm{X}$ chromosome, but their region of expression in females will depend on a mosaic pattern of X-inactivation. Secondly, some X-linked genes may be differentially expressed in male and female brains. Thirdly, many X-linked genes escape inactivation either partially or completely, lacking a functional homologue on the Y chromosome, consequently they are potentially haploinsufficient in males. Fourthly, X-linked genes may be subject to genomic imprinting, expressed only from the allele inherited from either mother or from father.

\section{$\mathrm{X}$-inactivation and sexual dimorphism}

During $\mathrm{X}$ chromosome inactivation, one of the pairs of homologous $X$ chromosomes present in the same nucleus is (partially) silenced (33). In mammalian cells, there is only one active $X$, irrespective of aneuploides. Inactivation proceeds in stages. First, there is a counting process, where the number of $\mathrm{X}$ chromosomes relative to autosomes is determined. Secondly, a choice is made about which $\mathrm{X}$ remains active. Silencing of the other $\mathrm{X}$ chromosome is initiated and spreads from the $\mathrm{X}$-inactivation centre. A range of heterochromatic features maintains the inactive state through subsequent cell divisions, even when the inactive chromosome is transferred into another species (e.g. human X into hybrid mouse cells). X-inactivation is a random process occurring very early on in development, at the blastocyst stage. Clones of cells deriving from the progenitor cells maintain the same pattern of $\mathrm{X}$-inactivation; we do not know how extensive these clones are in brain, or whether they are selected according to any particular pattern depending on the parent of origin.

Skewing from the expected 50/50 ratio may occur simply by chance, extremely skewed inactivation patterns can result from the mutations of the $\mathrm{X}$-inactivation centre, or from large deletions of part of the $\mathrm{X}$ chromosome. Potentially, any characteristic associated with an X-linked polymorphism, which is subject to random X-inactivation would be expressed differently in dichorionic monozygotic (MZ) twin girls, than in MZ boys because even 'identical' female twins are not identical in terms of their random pattern of $\mathrm{X}$-inactivation. Theoretically, we would expect greater diversity of phenotype in any trait linked to an inactivated allele, in females. Accordingly, we should be able to identify cognitive or behavioural traits that are influenced by X-linked genes (subject to inactivation) by looking at within-MZ pair correlations for 
sexual dimorphism. Examining data from a large twin study to test this hypothesis, Loat et al. (34) found that prosocial behaviour, verbal skills and peer relationships were influenced in the predicted direction (MZ female pairs less similar than MZ male pairs), although the effect size was very small. The hypothesis also predicts female dizygotic (DZ) pairs should be more similar than male DZ pairs for equivalent traits, because males receive only one of their mother's two X chromosomes. Assuming each son receives a different X chromosome, with functionally distinct alleles, such allelic differences will be exaggerated to their full extent. On the other hand, females would theoretically have a more mixed picture, which is complicated by allelic heterogeneity and X-inactivation. Loat et al. (34) found that this prediction was supported in terms of the phenotypes prosocial behaviour and verbal skills, supporting their hypothesis that X-linked genes do influence these traits directly. Incidentally, they did not find greater male variance for these X-linked traits, implying the $\mathrm{X}$-inactivation 'male extremes' hypothesis may not be valid, at least in terms of prosocial behaviour and verbal abilities.

\section{Genetic sex: models of sexual dimorphism}

To work out the potential impact of the genetic sex of cells, independent of gonadal phenotype, on brain development and function we must develop model systems. The preferred model is the mouse, in which it has been proved possible to manipulate the sexdetermining region of the $\mathrm{Y}$ chromosome in ingenious ways (35). Females that have a Y chromosome but lack Sry (the sex-determining gene necessary for the development of the testis) can be produced. Males can be produced with two X chromosomes plus a functioning copy of Sry. Comparisons can then be made between mice with four different genotypes (XX, XY, XX Sry and $\mathrm{XY}^{-}$Sry). Brain phenotypes that appear to be directly influenced by sex-chromosomal genes (independent of gonadal sex) can then be studied. Arnold and Burgoyne reviewed the evidence (35). Males with a Y chromosome $(+$ Sry $)$ have male-typical vasopressin innervation of the lateral septum. So do females with the Y chromosome that lacked Sry. XX females in general have less vasopressin innervation than $\mathrm{XY}$ males. Vasopressin is thought to play a critical role in social affiliation and to enhance aggression (36), thus the finding is consistent with sexual dimorphism in mice; males are substantially more aggressive than females. Further support for the role of sex-chromosome-linked genes in the promotion of aggression has recently been published (13); female mice with a Y chromosome lacking Sry $\left(\mathrm{XY}^{-}\right)$are much more aggressive than $\mathrm{XX}$ females (and substantially more aggressive even than $\mathrm{XX}+$ Sry females or $\mathrm{XY}+$ Sry males). Maternal behaviour also appears to be influenced directly by sex-chromosome-linked genes. Several measures of parental behaviour are more typically female in those with two X chromosomes (provided they lack Sry) than in those with an $\mathrm{XY}^{-}$Sry genotype. However, gonadal sex does also play a role, and there is a substantial negative effect of Sry on pup retrieval latency and number of pups retrieved, so XX + Sry females look very similar to normal males in this respect. The implication is that both sex-chromosome complement, and gonadal sex, influence social behaviour. Mechanisms by which the sex chromosomes are responsible for these findings are unknown, but could include the presence of a Y chromosome gene (other than Sry), or haploinsufficiency for an X-linked gene, or X-linked imprinting.

Some X-linked genes are expressed differently, depending on whether they are in male or female brains. In mice, six X-linked homologues of Y-linked genes (Usp9x, Ube1x, Smcx, Eif2s $3 x$, Utx and $D b x$ ) are expressed at significantly higher levels in adulthood in females than in males (37), irrespective of their $\mathrm{X}$-inactivation status, and gonadal status. The $\mathrm{X}$ and $\mathrm{Y}$ homologues of three genes in particular, Usp $9 x / y$, Ube $1 x / y$ and Eif2s $3 x / y$, appear to have acquired different functions and expression patterns in males and females. Sexually dimorphic expression of Usp $9 x$ is localized to specific brain regions such as neocortex (38). XX mice have higher levels of Eif $2 s 3 x$ mRNA expression than XY mice, irrespective of their gonadal sex (i.e. whether or not they have Sry). This suggests that sexually dimorphic expression of the Eif $2 s 3 x$ gene is a consequence of sex-chromosome complement (39).

\section{Genes escaping $X$-inactivation and sexual dimorphism}

Pairing between the $\mathrm{X}$ and $\mathrm{Y}$ chromosomes in the $2.7 \mathrm{Mb}$ pseudoautosomal region (PAR1) at the tip of the short arm $(\mathrm{Xp})$ is obligatory in male meiosis, and there is a second $330 \mathrm{~kb}$ pseudoautosomal region at the tip of $\mathrm{Xq}$ (PAR2). Genes in the PAR1 region are identical on both chromosomes, and escape inactivation, as do most genes in PAR2. Many X-linked genes outside these regions escape inactivation too (40). This is surprising because, beyond the PAR, only 25 genes have functional homology with the $\mathrm{Y}$ chromosome (41). If many $\mathrm{X}$-linked genes with no $\mathrm{Y}$ chromosome equivalent escape X-inactivation, a potential mechanism exists for sexually dimorphic expression; XY males could be haploinsufficient relative to $\mathrm{XX}$ females. Carrel and Willard (40) discovered only about $65 \%$ of X-linked genes are completely inactivated in normal XX females. A further $20 \%$ are inactivated in some, but not all cells, and $15 \%$ consistently escape inactivation. The implication of this remarkable research is that females have considerable heterogeneity in gene expression. At least $15 \%$ of X-linked genes are likely to be expressed at higher levels in females than males, but an additional 
$10 \%$ show heterogeneous X-inactivation. Could this mechanism have evolved to engender greater diversity in the female phenotype, than in males who will necessarily express only a single copy of such genes?

Nguyen and Disteche (19) used array expression profiles to study global transcriptional output from the mammalian X chromosome compared with the rest of the genome. Since only one X chromosome is present in males, and in females much of the second $\mathrm{X}$ is inactivated, there should, in theory, be a doubling of the product output of each such X-linked gene in order to match autosomal gene dosage. Dosage-dependent differences in chromosome-specific gene expression would be detected by comparing the mean global expression of X-linked genes to that of autosomal genes. If no compensation did occur, the X-autosome expression ratio would be 0.5 , otherwise it would be unity. The calculated ratio is indeed close to unity in adult somatic tissues. Targeting specifically the $15 \%$ of genes that escape $\mathrm{X}$-inactivation in females with two $\mathrm{X}$ chromosomes, Nguyen and Disteche (19) found the average female to male expression ratio to be 1.11 in humans (relatively few X-linked genes escape $\mathrm{X}$-inactivation in mice: evolution seems to have influenced a peculiarly human arrangement). Nevertheless, there was a wide variation in the observed female-to-male ratio for the 27 genes investigated (0.12.94). This implies sexually dimorphic expression of some such genes can occur, and may have functional consequences. However, there were in general rather low levels of expression from 'escape' genes on the inactive $\mathrm{X}$ chromosome, so gross dosage may not be much affected. One of the most interesting findings concerned X-linked gene expression in brain. Exceptionally highly expressed X-linked genes (where the transcriptional output is more than doubled) are relatively common in human brain, but unusual in other somatic tissues. A similar observation can be made in the brain tissues of other mammalian species, including chimpanzee, gorilla and macaque, independent of gender. Genes that are expressed both in brain and in somatic tissues are, if biased one way or the other, substantially more likely to be over-expressed in brain. How this upregulation is achieved is, at present, unknown.

\section{Mouse models of $X$ monosomy}

If there are adequate mechanisms to upregulate the single $\mathrm{X}$ chromosome in males, it might be thought that syndromes of X monosomy would be associated with relatively few phenotypic consequences. In contrast to the human, mice have proportionately far fewer genes that escape X-inactivation (42). For many years, $\mathrm{X}$-monosomic mice were considered not a good model for Turner syndrome (human X monosomy) because they are fertile, and do not have gross phenotypic anomalies in terms of growth or cognitive abilities. On the other hand, there are subtle differences in their behaviour compared with XX mice, and these have been the subjects of recent investigation. 39,X mice can be generated by the fertilization of a normal gamete by a sex-chromosome null gamete, and therefore are free from the problem of mosaicism - which might potentially influence the correct interpretation of $\mathrm{X}$-monosomic data in humans (43). 39,X mice show greater fear reactivity than $40, \mathrm{XX}$ mice (44); they spend less time on the open arm of the elevated plus maze, a standard method for measuring anxiety in mouse models. Importantly, careful controls show that excessive anxiety associated with $\mathrm{X}$ monosomy is not influenced by the stage of the oestrus cycle, locomotor activity, response to novelty or the parental origin of the single X chromosome. What candidate genes might be responsible? This might seem fairly straightforward to investigate because of the paucity of mouse X-linked genes escaping inactivation and therefore being potentially haploinsufficient. One prime suspect was the steroid sulphatase gene Sts, the product of which is known to interact with gamma-aminobutyric acid $(\mathrm{GABA})_{\mathrm{A}}$ receptors. The GABA system plays a critical role in the pathophysiology of anxiety (45) and Sts enzymatic activity correlates with aggression (46). Unfortunately, that hypothesis was not supported (44): in a partial X-deletion mouse model, designed to ensure that both Sts expression and the expression levels of associated $\mathrm{GABA}_{\mathrm{A}}$ subunits were normal, excessive fear reactivity persisted. Therefore, it must be related to haploinsufficiency for a different (as yet unidentified) X-linked gene that escapes inactivation in mice.

\section{Human X monosomy}

The clinically defined condition of Turner syndrome is due to the partial or complete loss of one of the sex chromosomes, either the second $\mathrm{X}$ chromosome or the $\mathrm{Y}$ chromosome (47). A contributory factor is oestrogen (and androgen) insufficiency. Since non-inactivated (hence potentially haploinsufficient) genes contribute to the development and maintenance of ovarian tissues (48), there is early degeneration of the ovaries. Turner syndrome is associated with short stature, due largely to haploinsufficiency for the SHOX gene, expressed from PAR1 (49), plus other variable physical feature. Females with Turner syndrome nearly always have normal verbal intelligence, although about $80 \%$ are deficient in terms of visuospatial abilities, such as the ability to complete a jigsaw puzzle (50). Arithmetical abilities are often seriously impaired too (51). Dosage-sensitive $\mathrm{X}$-linked genes appear to be involved in numerical cognitive skills and spatial intelligence (52).

However, one of the most striking associated behavioural phenotypic features concerns social adjustment. Many females with Turner syndrome in childhood and adulthood have limited number of friends and 
may become socially isolated (53). There is a substantially increased risk of autism (at least 200 times) (54). Profound face and emotion recognition deficits affect a minority and they cannot easily determine the direction of other's eye gaze and line of sight (55). The nature and severity of these social cognitive deficits is similar to that seen in cases of bilateral amygdalectomy or UrbachWiethe disease. Consequently, haploinsufficiency for one or more X-linked genes could have a specific impact on development of the amygdala and its connections with cortical centres involved in the processing of social cognitions, the 'social brain' (56). We have attempted to identify the genes responsible, using a deletion-mapping technique. By this means, we have discovered that one or more candidates lie on the proximal short arm, near the centromere, at Xp 11.4 (57). A cluster of genes that escapes $\mathrm{X}$-inactivation can be found at the same location (40). Haploinsufficiency for X-linked genes in Turner syndrome influences brain structure. Deletion of the critical region of the $\mathrm{X}$ chromosome at Xp11.4, whether terminal or interstitial, results in an enlarged amygdala and increases in grey matter volume in the orbitofrontal cortex bilaterally, close to a region implicated in emotional learning (57). The increase in amygdala size is even greater than the relative difference normally found between males and females (58) implying that haploinsufficiency for one or more dosage sensitive genes might contribute to sexual dimorphism in this structure. Replication, of the volumetric differences in the amygdala of Turner subjects, has been found by some investigators (59) but not by all (60). Other structural brain changes in X monosomy include the parieto-occipital region (possibly related to the visuospatial and arithmetic difficulties), the cerebellum and the basal ganglia and the superior temporal gyrus (60). The superior temporal gyrus has efferent connections with the parietal lobes and the prefrontal cortex, both of which are structurally anomalous in XO females; so sexual dimorphism in the cortical thickness of certain regions could reflect the actions of X-linked genes (61).

\section{X-linked imprinting and sexual dimorphism}

The theory that X-linked imprinting could be a mechanism for sexual dimorphism arose from the observation that females with X-monosomic Turner syndrome differed in their cognitive and behavioural phenotypes according to the parental origin of their single X chromosome (62). Imprinted genes are inherited in duplicate, but only one is expressed; this might be either the maternal or the paternal allele. Imprinting of autosomal genes should not bring about any bias in expression of the phenotype by sex, but because of the asymmetrical inheritance of the $\mathrm{X}$ chromosome (males invariably inherit only the maternal X) sexual dimorphism could accompany X-linked imprinting. Sexually dimorphic gene expression could occur whether the expressed allele was paternal (inherited only by females) or maternal provided the latter was subject to random X-inactivation (63), in which case average female expression would be half-male expression. Skuse et al. (62) found that X-monosomic females with a single paternal $\mathrm{X}$ were, in general, better socially adjusted than those with a single maternal $X$. These differences were reflected in normal male:female behaviour, on the same measures, implying X-linked imprinting could contribute to human sexual dimorphism in social cognitive competence.

$X$-linked imprinting in $\boldsymbol{X}$-monosomic mice The identification of genes that could be imprinted on the $\mathrm{X}$ chromosome and contribute to sexual dimorphism required the generation of a mouse model. 39, $\mathrm{X}$ mice were tested for behavioural inhibition. $45, \mathrm{X}^{\mathrm{m}}$ (maternal $\mathrm{X}$-only) Turner syndrome females are less competent than either $45, \mathrm{X}^{\mathrm{p}}$ (paternal X-only) or $46, \mathrm{XX}$ females at a simple task (64), which requires the inhibition of a prepotent response (62). Males are also less competent at the task than normal females. The Y-maze, a visual, non-spatial, serial reversal-learning paradigm, was used in which mice are trained to go down one of the two goal arms to collect a foodstuff reinforcer. $39, \mathrm{X}^{\mathrm{m}}$ mice showed impaired reversal learning. There were no significant differences in performance between the $39, \mathrm{X}^{\mathrm{p}}$ and 40,XX mice. Male-female performance differences in the task were in the predicted direction. The Xlr 3 gene is the candidate $(64,65)$; it is imprinted and maternally expressed. Studies of normal male and female mice indicate the gene is paternally silenced and subject to $\mathrm{X}$-inactivation. Therefore, expression is sexually dimorphic (approximately twice as great in males as females).

\section{$X$-linked imprinting in $X$-monosomic humans} Structural brain differences in Turner syndrome females reflect the parental origin of their single X chromosome. $\mathrm{X}$-linked imprinting influences the volume of the superior temporal gyrus (66), as well as occipital white matter and cerebellar grey matter (67). 45, $\mathrm{X}^{\mathrm{m}}$ women have larger right hippocampal volume than $45, \mathrm{X}^{\mathrm{p}}$ subjects $(60)$, a finding that could be linked to the observation that $45, \mathrm{X}^{\mathrm{p}}$ females have poorer visual memory than $45, \mathrm{X}^{\mathrm{m}}$ females, despite their better social adjustment $(68) .45, \mathrm{X}^{\mathrm{m}}$ females also possess significantly smaller volumes of caudate nucleus and thalamus than $45, \mathrm{X}^{\mathrm{p}}$ subjects. Whilst there is consistent evidence concerning the sexual dimorphism of the superior temporal gyrus (61), white and grey matter differences by gender in other structures 
potentially influenced by X-linked imprinted genes are less clearly defined.

\section{Conclusions}

X-linked genes are under strong evolutionary pressure, and are evolving more rapidly in humans than in other species. They are preferentially expressed in the brain, and are likely to contribute to increasing cortical complexity and size. Sexual dimorphism in the actions of X-linked genes is to be expected. At least four different mechanisms could lead to differential expression of $\mathrm{X}$-linked genes in males and females, and evidence is available to support each one of them. The first candidate genes have recently been discovered.

\section{Acknowledgements}

Work by the author cited in this review has been funded by the Wellcome Trust, the National Alliance for Autism Research, the Child Growth Foundation, and the Nancy Lurie Marks Family Foundation.

\section{References}

1 Khaitovich P, Hellmann I, Enard W, Nowick K, Leinweber M, Franz H, Weiss G, Lachmann M \& Paabo S. Parallel patterns of evolution in the genomes and transcriptomes of humans and chimpanzees. Science 2005309 1850-1854.

2 Preuss TM, Caceres M, Oldham MC \& Geschwind DH. Human brain evolution: insights from microarrays. Nature Reviews Genetics 20045 850-860.

3 Hurst LD. Evolutionary genomics. Sex and the X. Nature 2001411 $149-150$.

4 Caceres M, Lachuer J, Zapala MA, Redmond JC, Kudo L, Geschwind DH, Lockhart DJ, Preuss TM \& Barlow C. Elevated gene expression levels distinguish human from non-human primate brains. PNAS 2003100 13030-13035.

$5 \mathrm{Gu} \mathrm{J} \& \mathrm{Gu} \mathrm{X}$. Further statistical analysis for genome-wide expression evolution in primate brain/liver/fibroblast tissues. Human Genomics $20041247-254$.

6 Dorus S, Vallender EJ, Evans PD, Anderson JR, Gilbert SL, Mahowald M, Wyckoff GJ, Malcom CM \& Lahn BT. Accelerated evolution of nervous system genes in the origin of Homo sapiens. Cell 2004119 1027-1040.

7 Check E. Genetics: the X factor. Nature $2005434266-267$.

8 Khil PP \& Camerini-Otero RD. Molecular features and functional constraints in the evolution of the mammalian X chromosome. Critical Reviews in Biochemistry and Molecular Biology 200540 313-330.

9 Charlesworth D \& Charlesworth B. Sex chromosomes: evolution of the weird and wonderful. Current Biology 200515 R129-R131.

10 Arnold AP, Wade J, Grisham W, Jacobs EC \& Campagnoni AT Sexual differentiation of the brain in songbirds. Developmental Neuroscience 199618 124-136.

11 Arnold AP. Sex chromosomes and brain gender. Nature Reviews Neuroscience 20045 701-708.

12 Dobyns WB, Filauro A, Tomson BN, Chan AS, Ho AW, Ting NT, Oosterwijk JC \& Ober C. Inheritance of most X-linked traits is not dominant or recessive, just X-linked. American Journal of Medical Genetics. Part A 2004129 136-143.
13 Gatewood JD, Wills A, Shetty S, Xu J, Arnold AP, Burgoyne PS \& Rissman EF. Sex chromosome complement and gonadal sex influence aggressive and parental behaviors in mice. Journal of Neuroscience $2006262335-2342$.

14 Jonasson Z. Meta-analysis of sex differences in rodent models of learning and memory: a review of behavioral and biological data. Neuroscience and Biobehavioral Reviews 200528 811-825.

15 Stavnezer AJ, McDowell CS, Hyde LA, Bimonte HA, Balogh SA, Hoplight BJ \& Denenberg VH. Spatial ability of XY sex-reversed female mice. Behavioural Brain Research 2000112 135-143.

16 Ross J, Roeltgen D \& Zinn A. Cognition and the sex chromosomes: studies in Turner syndrome. Hormone Research 200665 47-56.

17 Zechner U, Wilda M, Kehrer-Sawatzki H, Vogel W, Fundele R \& Hameister $\mathrm{H}$. A high density of X-linked genes for general cognitive ability: a run-away process shaping human evolution? Trends in Genetics 200117 697-701.

18 Graves JA, Gecz J \& Hameister H. Evolution of the human X - a smart and sexy chromosome that controls speciation and development. Cytogenetic and Genome Research 200299 141-145.

19 Nguyen DK \& Disteche CM. Dosage compensation of the active X chromosome in mammals. Nature Genetics 200638 47-53.

20 Lahn BT \& Page DC. Four evolutionary strata on the human X chromosome. Science 1999286 964-967.

21 Spelke ES. Sex differences in intrinsic aptitude for mathematics and science?: a critical review American Psychologist 2005 60 950-958.

22 Connellan J, Baron-Cohen S, Wheelwright S, Batki A \& Ahluwalia J. Sex differences in human neonatal social perception. Infant Behavior and Development 200023 113-118.

23 Rutter M, Caspi A, Fergusson D, Horwood LJ, Goodman R, Maughan B, Moffitt TE, Meltzer H \& Carroll J. Sex differences in developmental reading disability: new findings from 4 epidemiological studies. Journal of the American Medical Association 2004 291 2007-2012.

24 Irwing P \& Lynn R. Sex differences in means and variability on the progressive matrices in university students: a meta-analysis. British Journal of Psychology 200596 505-524.

25 Blinkhorn S. Intelligence: a gender bender. Nature 2005438 31-32.

26 Jamain S, Quach H, Betancur C, Rastam M, Colineaux C, Gillberg IC, Soderstrom H, Giros B, Leboyer M, Gillberg C \& Bourgeron T. Mutations of the X-linked genes encoding neuroligins NLGN3 and NLGN4 are associated with autism. Nature Genetics 200334 27-29.

27 Thomas NS, Sharp AJ, Browne CE, Skuse D, Hardie C \& Dennis NR. $\mathrm{Xp}$ deletions associated with autism in three females. Human Genetics 1999104 43-48.

28 Laumonnier F, Bonnet-Brilhault F, Gomot M, Blanc R, David A, Moizard MP, Raynaud M, Ronce N, Lemonnier E, Calvas P, Laudier B, Chelly J, Fryns JP, Rogers HH, Hamel BC, Andres RC, Barthelemy C, Moraine C \& Briault S. X-linked mental retardation and autism are associated with a mutation in the NLGN4 gene, a member of the neuroligin family. American Journal of Human Genetics $2004 \mathbf{7 4}$ 552-557.

29 Gauthier J, Bonnel A, St-Onge J, Karemera L, Laurent S, Mottron L, Fombonne E, Joober R \& Rouleau GA. NLGN3/NLGN4 gene mutations are not responsible for autism in the Quebec population. American Journal of Medical Genetics. Part B. Neuropsychiatric Genetics 2005132 74-75.

30 Vincent JB, Kolozsvari D, Roberts WS, Bolton PF, Gurling HM \& Scherer SW. Mutation screening of X-chromosomal neuroligin genes: no mutations in 196 autism probands. American Journal of Medical Genetics. Part B. Neuropsychiatric Genetics $200412982-84$.

31 Volkmar FR, Lord C, Bailey A, Schultz RT \& Klin A. Autism and pervasive developmental disorders. Journal of Child Psychology and Psychiatry 200445 135-170.

32 Hermens DF, Kohn MR, Clarke SD, Gordon E \& Williams LM. Sex differences in adolescent ADHD: findings from concurrent EEG and EDA. Clinical Neurophysiology 2005116 1455-1463. 
33 Chow JC, Yen Z, Ziesche SM \& Brown CJ. Silencing of the mammalian X chromosome. Annual Review of Genomics and Human Genetics 20056 69-92.

34 Loat CS, Asbury K, Galsworthy MJ, Plomin R \& Craig IW. X inactivation as a source of behavioural differences in monozygotic female twins. Twin Research 20047 54-61.

35 Arnold AP \& Burgoyne PS. Are XX and XY brain cells intrinsically different? Trends in Endocrinology and Metabolism 200415 6-11.

36 Ferris CF. Vasopressin/oxytocin and aggression. Novartis Foundation Symposium 2005268 190-198.

$37 \mathrm{Xu}$ J, Burgoyne PS \& Arnold AP. Sex differences in sex chromosome gene expression in mouse brain. Human Molecular Genetics 2002 11 1409-1419.

$38 \mathrm{Xu}$ J, Taya S, Kaibuchi K \& Arnold AP. Sexually dimorphic expression of Usp9x is related to sex chromosome complement in adult mouse brain. European Journal of Neuroscience 200521 3017-3022.

$39 \mathrm{Xu}$ J, Watkins R \& Arnold AP. Sexually dimorphic expression of the $\mathrm{X}$-linked gene Eif2s3x mRNA but not protein in mouse brain. Gene Expression Patterns 20066 146-155.

40 Carrel L \& Willard HF. X-inactivation profile reveals extensive variability in X-linked gene expression in females. Nature 2005 434 400-404.

41 Ross MT, Grafham DV, Coffey AJ, Scherer S, McLay K, Muzny D, Platzer M, Howell GR, Burrows C Bird CP et al. The DNA sequence of the human X chromosome. Nature 2005 434 325-337.

42 Tsuchiya KD \& Willard HF. Chromosomal domains and escape from $\mathrm{X}$ inactivation: comparative $\mathrm{X}$ inactivation analysis in mouse and human. Mammalian Genome 200011 849-854.

43 Henn W \& Zang KD. Mosaicism in Turner's syndrome. Nature 1997390569.

44 Isles AR, Davies W, Burrmann D, Burgoyne PS \& Wilkinson LS. Effects on fear reactivity in XO mice are due to haploinsufficiency of a non-PAR X gene: implications for emotional function in Turner's syndrome. Human Molecular Genetics 200413 1849-1855.

45 Nemeroff $\mathrm{CB}$. The role of GABA in the pathophysiology and treatment of anxiety disorders. Psychopharmacology Bulletin 2003 37 133-146.

46 Le RI, Mortaud S, Tordjman S, Donsez-Darcel E, Carlier M, Degrelle H \& Roubertoux PL. Genetic correlation between steroid sulfatase concentration and initiation of attack behavior in mice. Behavior Genetics 199929 131-136.

47 Sybert VP \& McCauley E. Turner's syndrome. New England Journal of Medicine 2004351 1227-1238.

48 James RS, Coppin B, Dalton P, Dennis NR, Mitchell C, Sharp AJ, Skuse DH, Thomas NS \& Jacobs PA. A study of females with deletions of the short arm of the X chromosome. Human Genetics 1998102 507-516.

49 Rao E, Weiss B, Fukami M, Rump A, Niesler B, Mertz A, Muroya K, Binder G, Kirsch S, Winkelmann M, Nordsiek G, Heinrich U, Breuning MH, Ranke MB, Rosenthal A, Ogata T \& Rappold GA. Pseudoautosomal deletions encompassing a novel homeobox gene cause growth failure in idiopathic short stature and Turner syndrome. Nature Genetics 199716 54-63.

50 Temple CM \& Carney RA. Patterns of spatial functioning in Turner's syndrome. Cortex 199531 109-118.

51 Molko N, Cachia A, Riviere D, Mangin JF, Bruandet M, LeBihan D, Cohen L \& Dehaene S. Brain anatomy in Turner syndrome: evidence for impaired social and spatial-numerical networks. Cerebral Cortex $200414840-850$.

52 Kesler SR, Menon V \& Reiss AL. Neurofunctional differences associated with arithmetic processing in Turner syndrome. Cerebral Cortex 200616 849-856.

53 McCauley E, Feuillan P, Kushner H \& Ross J. Psychosocial development in adolescents with Turner syndrome. Journal of Developmental and Behavioral Pediatrics 200122 360-365.
54 Creswell C \& Skuse D. Autism in association with Turner syndrome: implications for male vulnerability. Neurocase $2000 \mathbf{5}$ 511-518.

55 Lawrence K, Campbell R, Swettenham J, Terstegge J, Akers R, Coleman M \& Skuse D. Interpreting gaze in Turner syndrome: impaired sensitivity to intention and emotion, but preservation of social cueing. Neuropsychologia $2003 \mathbf{4 1} 894-905$.

56 Adolphs R. Investigating the cognitive neuroscience of social behavior. Neuropsychologia $2003 \mathbf{4 1} 119-126$.

57 Good CD, Lawrence K, Thomas NS, Price CJ, Ashburner J, Friston KJ, Frackowiak SJ, Oreland L \& Skuse DH. Dosage sensitive $\mathrm{X}$-linked locus influences the development of amygdala and orbitofrontal cortex, and fear recognition in humans. Brain 2003126 2431-2446

58 Good CD, Johnsrude I, Ashburner J, Henson RN, Friston KJ \& Frackowiak RS. Cerebral asymmetry and the effects of sex and handedness on brain structure: a voxel-based morphometric analysis of 465 normal adult human brains. Neuroimage 2001 14 685-700.

59 Kesler SR, Garrett A, Bender B, Yankowitz J, Zeng SM \& Reiss AL. Amygdala and hippocampal volumes in Turner syndrome: a highresolution MRI study of X-monosomy. Neuropsychologia 200442 1971-1978.

60 Cutter WJ, Daly EM, Robertson DM, Chitnis XA, van Amelsvoort TA, Simmons A, Ng VW, Williams BS, Shaw P \& Conway GS. Influence of X chromosome and hormones on human brain development: a magnetic resonance imaging and proton magnetic resonance spectroscopy study of Turner syndrome. Biological Psychiatry $200659273-283$.

61 Im K, Lee JM, Lee J, Shin YW, Kim IY, Kwon JS \& Kim SI. Gender difference analysis of cortical thickness in healthy young adults with surface-based methods. Neuroimage 200631 31-38.

62 Skuse DH, James RS, Bishop DV, Coppin B, Dalton P, AamodtLeeper G, Bacarese-Hamilton M, Creswell C, McGurk R \& Jacobs PA. Evidence from Turner's syndrome of an imprinted X-linked locus affecting cognitive function. Nature $1997 \mathbf{3 8 7}$ 705-708.

63 Davies W, Isles AR, Burgoyne PS \& Wilkinson LS. X-linked imprinting: effects on brain and behaviour. Bioessays $2006 \mathbf{2 8}$ 35-44.

64 Davies W, Isles A, Smith R, Karunadasa D, Burrmann D, Humby T, Ojarikre O, Biggin C, Skuse D, Burgoyne P \& Wilkinson L. Xlr3b is a new imprinted candidate for X-linked parent-of-origin effects on cognitive function in mice. Nature Genetics $200537625-629$.

65 Raefski AS \& O'Neill MJ. Identification of a cluster of X-linked imprinted genes in mice. Nature Genetics 200537 620-624.

66 Kesler SR, Blasey CM, Brown WE, Yankowitz J, Zeng SM, Bender BG \& Reiss AL. Effects of X-monosomy and X-linked imprinting on superior temporal gyrus morphology in Turner syndrome. Biological Psychiatry 200354 636-646.

67 Brown WE, Kesler SR, Eliez S, Warsofsky IS, Haberecht M, Patwardhan A, Ross JL, Neely EK, Zeng SM, Yankowitz J \& Reiss AL. Brain development in Turner syndrome: a magnetic resonance imaging study. Psychiatry Research $2002116187-196$.

68 Bishop DV, Canning E, Elgar K, Morris E, Jacobs PA \& Skuse DH. Distinctive patterns of memory function in subgroups of females with Turner syndrome: evidence for imprinted loci on the $\mathrm{X}$-chromosome affecting neurodevelopment. Neuropsychologia $200038712-721$.

Received 24 April 2006

Accepted 20 July 2006 